\title{
PAST PERFORMANCE AND FUTURE PERSPECTIVES OF BURNOUT RESEARCH
}

\author{
WB SCHAUFELI \\ Department of Psychology and Research Institute Psychology \& Health \\ Utrecht University \\ The Netherlands
}

\begin{abstract}
After a brief introduction on the history of burnout, this article reviews the past performance of burnout research by answering ten key-questions: (1) How can burnout be assessed?; (2) Is burnout limited to the human services?; (3) Is burnout a mental disorder; (4) What is the prevalence of burnout?; (5) Is burnout a global phenomenon?; (6) Is burnout relevant for organisations; (7) What are the causes of burnout?; (8) What are the consequences of burnout?; (9) How can burnout be explained?; (10) Are burnout interventions effective? In the concluding section a future research agenda is drafted on the bases of the answers given to the previous questions. This agenda includes such issues as the measurement and conceptualisation of burnout, mild and severe forms of burnout, epidemiological and cross-cultural perspectives, organisational outcomes, longitudinal investigations, theoretical explanations, and interventions.
\end{abstract}

\section{OPSOMMING}

$\mathrm{Na}$ ' $\mathrm{n}$ kort inleiding oor die geskiedenis van uitbranding gee hierdie artikel ' $\mathrm{n}$ oorsig van vorige prestasie van navorsing ten opsigte van uitbranding deur tien sleutelvrae te beantwoord: (1) Hoe kan uitbranding bepaal word?; (2) Is uitbranding beperk tot die mens-dienste?; (3) Is uitbranding 'n geestesafwyking?; (4) Wat is die voorkoms van uitbranding?; (5) Is uitbranding 'n wêreldwye verskynsel?; (6) Is uitbranding relevant vir organisasies?; (7) Wat is die oorsake van uitbranding?; (8) Wat is die gevolge van uitbranding?; (9) Hoe kan uitbranding verklaar word?; (10) Is uitbrandingsingrepe effektief? In die gevolgtrekking word 'n toekomstige navorsingsagenda op grond van die antwoorde op die voorafgaande vrae opgestel. Hierdie agenda sluit aangeleenthede soos die meting en konseptualisering van uitbranding, matige en ernstige vorme van uitbranding, epidemiologiese en kruiskulturele perspektiewe, organisasie-uitkomste, longitudinale ondersoeke, teoretiese verklarings en intervensies in.

It's over 20 years ago that a scientific journal editor returned the first empirical paper on the Maslach Burnout Inventory (MBI) to the authors - without even reading it - with the words: “...we do not publish 'pop psychology", (Maslach \& Jackson, 1984, p. 139). To date, a search in specialised databases such as PsychLit and MedLine reveals over 6,000 scientific publications with 'burnout' in the title. Moreover, Schaufeli and Enzmann (1998) calculated that the initially cursed MBI was used in over $90 \%$ of all empirical articles! Obviously, academic burnout research flourished in the recent past, despite its 'pop' background as a lay-term.

How to explain this triumphal march from the back streets of the ghettos, where the metaphor 'burnout' was first used as a colloquial term for a state of mental exhaustion by poverty lawyers, to respectable universities and fancy editorial offices? Probably the main reason is that in our contemporary western societies many employees seem to suffer from work related mental problems, such as burnout. For instance, a recent survey of the European Commission indicated that after back pain (33\%), stress $(28 \%)$ and fatigue $(23 \%)$ ranked on places 2 and 3 , respectively, of the most frequently experienced occupational health problems (Paoli, 2001). Consequently, work related mental problems constitute a significant social problem in many countries. In The Netherlands after 'common colds, flu, and minor respiratory symptoms', 'mental problems' are the second most frequent cause of sickness absenteeism, whereas stress-related disorders are the most frequent diagnosis for being work disabled (Houtman, Smulders \& Klein Hesselink, 2002). It seems that rather than being an exception, the situation in the Netherlands is typical of most developed western countries (Landsbergis, 2003).

A workforce that seems to suffer to such an extent from mental problems calls for further research that in many countries is fostered by grants from governmental bodies, trade unions,

Requests for copies should be addressed to: WB Schaufeli, Department of Psychology and Research Institute Psychology and Health, Utrecht University, The Netherlands pension funds, research councils, public institutions, and private companies. For instance, in The Netherlands a large-scale concerted research action on occupational fatigue was initiated in 1996 (see http://pva.magw.nl/content.uk.html). And once research on a particular subject is conducted on a certain scale, it tends to generate more research on the same topic - a dynamic that is inherent to science. As in the case of burnout research might accumulate to such an extent that it may become 'fashionable'.

In sum: burnout has been a well-liked topic across the past 25 years, not only as 'pop' psychology, but also in academia. The popularity of applied burnout research stems from the fact that in today's society many suffer from work-related mental problems, which - for that very reason - constitute a social, economic and political problem that calls for further research. Moreover, the popularity of burnout research is further enhanced by the self-perpetuating nature of science.

The purpose of this article is not to review the extensive literature on burnout that has been accumulated so far. This has been done elsewhere (cf. Lee \& Ashforth, 1996; Schaufeli \& Enzmann, 1998; Maslach, Schaufeli \& Leiter, 2001; Schaufeli \& Buunk, 2002). Rather, I would like to briefly summarise the main achievements of burnout research so far (past performance) and discuss the further outlook (future research). However, before embarking on this endeavour and in order to set the stage, a concise history of burnout is presented first.

\section{A brief history of burnout}

The term 'burnout' - a metaphor to describe a state or process of mental exhaustion - was first used in the United States in late sixties and early seventies of the past century, although the particular experience itself is likely to be of all times and all places. This is illustrated by the fact that William Shakespeare wrote over four centuries ago: "She burnt out loue, as straw with fire flameth. She burnt out loue, as soon as straw out burneth". Many have speculated about the reason why this powerful metaphor appeared on the scene at that particular time and at 
that particular place. To date, no satisfactory comprehensive explanation exists for the 'discovery' of burnout and most probably there never will. Nevertheless, two conclusions can be drawn from the 'discovery' of burnout.

First, the burnout metaphor was initially used as a colloquial term by professionals such as, poverty lawyers, social workers, psychiatrists, teachers, probation officers, and hospice counsellors. They used it to denote their gradual energy depletion and loss of motivation and commitment that was often associated with a wide array of other physical and mental symptoms. The burnout concept entered academia through the back door, so to speak. And this had its price, as Maslach and Jackson (1984, p. 139) noted: "Because it has a catchy ring to it, burnout is sometimes immediately dismissed as fad or pseudoscientific jargon that is all surface and has no substance". Although almost twenty years later the situation has improved, burnout is still not officially recognised as a psychiatric diagnosis, despite the fact that this was predicted in an editorial of The Lancet already in 1994. Second, two persons almost simultaneously but independently stumbled across 'burnout': Herbert Freudenberger and Christina Maslach. Each of them represents the starting point of a particular approach to burnout that developed in almost total isolation from the other approach. Freudenberger - a practicing psychiatrist - represents the clinical approach that considers 'the burnout syndrome' as a mental disorder that is mainly caused by personal characteristics, such as intra-personal conflicts, dysfunctional personality traits or cognitions, and wrong coping patterns. The emphasis of this approach, that is particularly advocated by practitioners, is on clinical observation, diagnosis, counselling, individual treatment, and rehabilitation and has lead to a myriad of do-it-yourself books, and - lately - websites. On the other hand, Maslach - a social psychological researcher - represents the scientific approach that considers interpersonal, social, and organisational factors as the root-causes of burnout. Researchers, who measure burnout in a standardised way, usually with selfreport questionnaires, have been successful in identifying its possible causes, correlates and consequences (see below).

Obviously, burnout was 'in the air' since almost immediately after its 'discovery' it became a very popular topic in the USA. In the first so-called pioneering phase the clinical approach prevailed and many articles were published in popular magazines and in periodicals for professionals such as teachers, social workers, and nurses. The mass media eagerly picked up the burnout concept and a tremendous proliferation of workshops, training and other interventions took place. Virtually no empirical research was carried out at this stage. In the next, socalled empirical phase this changed dramatically. As soon as the first easy to administer self-report inventories appeared in the early 1980's - most notably the Maslach Burnout Inventory (MBI) - research lifted off. From the very beginning, the MBI dominated the field, even to such an extent that the definition that was implied in this instrument became the definition of burnout: "Burnout is a syndrome of emotional exhaustion, depersonalisation, and reduced personal accomplishment that can occur among individuals who do 'people work' of some kind" (Maslach \& Jackson, 1986, p. 1).

The five most important developments that took place in the past two decades from the start of the empirical phase are: (1) burnout became a serious scientific topic and empirical research boomed, as witnessed by thousands of publications; (2) burnout started to draw attention in countries outside North America, particularly Europe; (3) after the introduction of the MBIGeneral Survey in 1996, employees outside the human services who do not do 'people work' - were researched as well; (4) over time, the quality of burnout research improved, more theory driven studies were carried out and longitudinal designs were employed; and (5) the concept of burnout is being supplemented by its positive antithesis - job engagement - so that the entire spectrum of workers' well-being is now covered.
Unfortunately, also after over 25 years, there is still little crossfertilisation between clinical practitioners and academic scholars, particularly in the USA - the home country of burnout. A slightly different picture can be seen in other countries, though. For instance, in the Netherlands where the concept of 'overstrain' (Dutch: 'overspannenheid') has a long tradition, dating back to the late $19^{\text {th }}$ century (Schmidt, 2000). 'Overstrain' - a phenomenon akin to burnout - is used as a lay-term as well as an official diagnostic label; it is common Dutch language and medical jargon. Traditionally, overstrain is also investigated by Dutch researchers since it appears as a major cause of sickness absence and work disablement. This means that already before the introduction of burnout in the Netherlands in the late eighties Dutch practitioners were trained to diagnose and treat 'overstrain', the phenomenon was scholarly investigated, and preventive programmes were implemented in organisations. Thus, in the Netherlands burnout - albeit disguised as overstrain - enjoys already for a long time the official (medical) status that is denied elsewhere. The concept of overstrain is firmly rooted both in practice and in academia, and practitioners, scientists and policy makers alike are used to collaborate on this issue. The existence of the concept of overstrain has also lead to the specific use of the label 'burnout', which in the Netherlands is employed to indicate chronic and severe 'overstrain'. So, instead of covering the entire spectrum from very mild to very severe symptoms, like in the USA, 'burnout' is used in the Netherlands to denote an endstate (i.e. mental disorder), whereas 'overstrain' is used for labelling milder burnout symptoms.

In sum: the reception of 'burnout' differs from country to country. In a country like the Netherlands (and perhaps Scandinavia) where a 'burnout' tradition avant la lettre existed two phenomena can be observed: (1) research as well as practice can be joined, including cross-fertilising collaboration between both fields; (2) the newly imported term 'burnout' does not replace the older term ('overstrain'), rather it is used in a more specific way supplementing the more traditional concept.

In the next section, I will elaborate on the past performance of burnout research by trying to answer ten key questions. Despite fundamental criticisms on burnout research as being repetitive, a theoretical, narrow, exclusively quantitative, and ethnocentric (Rösing, 2003) some progress has been made in the past quarter of a century in understanding the phenomenon.

\section{Past performance of burnout research: The answers to ten} key-questions

The ten questions (Q) below are more or less inspired by Schaufeli, Maslach and Marek (1993), who asked themselves in the concluding chapter of an edited volume on professional burnout "What do we need?", thereby referring to the future research needs. So in a way, the answers (A) reflect the (lack of) progress made in the past decade.

\section{Q: How can burnout be assessed?}

\section{A: With the Maslach Burnout Inventory, albeit with some critical remarks}

Practically speaking almost all burnout research uses the MBI (see above), which originally has two versions, one for employees working in the human services (Human Services Survey - HSS) and one for educators (Educators Survey - ES). The main difference being that 'recipients' in the former is replaced by 'students' in the latter (Maslach \& Jackson, 1986). The MBI-HSS/ES assesses three burnout dimensions: (1) emotional exhaustion; (2) depersonalisation (a callous, indifferent and cynical attitude towards recipients or students); and (3) personal accomplishment (reversed). In fact, these represent an energetic (e.g., feeling used up), attitudinal (e.g., being cynical) and evaluative (e.g., doubting one's competence) component, respectively.

Generally speaking, the psychometric properties of the MBI are encouraging (for an overview see: Schaufeli, Enzmann \& Girault, 1993; Schaufeli \& Enzmann, 1998, pp. 50-54). More particularly, 
the hypothesised three factor structure of the MBI has been confirmed in numerous studies (recently by e.g., Gorter, Albrecht, Hoogstraten \& Eijkman, 1999; Boles, Dean, Ricks, Short \& Wang, 2000). Only occasionally somewhat deviant results are reported, probably because of sampling bias. For example, Densten (2001) reports five factors in a sample of Australian law enforcement managers. The only more or less systematic exception to the supremacy of the three-factor structure is the finding that sometimes a two-factor model in which exhaustion and depersonalisation are collapsed fits better (or equally well) to the data (e.g. Holland, Michael \& Kim, 1994). For that reason, Green Walkey and Taylor (1991) have called exhaustion and depersonalisation the 'core of burnout'.

When slightly adapted versions of the MBI-HSS/ES were used outside the targeted professions, psychometric results were rather disappointing (e.g. Evans \& Fisher, 1993; Boles et al., 2000). The fact that, obviously, the MBI should be used exclusively in those occupational contexts it has been designed for - human services and education - has lead to the development of a version that can be used universally: the MBIGeneral Survey (see Q 2 below). The MBI-GS contains dimensions similar to the original version, except that the items do not explicitly refer to recipients or students (Schaufeli, Leiter, Maslach \& Jackson, 1996). Accordingly, the MBI-GS dimensions have been slightly renamed as: exhaustion, cynicism, and professional efficacy (reversed).

Like with the original version, this three-factor structure of the MBI-GS is generally confirmed (Taris, Schreurs \& Schaufeli, 1999; Schutte, Toppinen, Kalimo \& Schaufeli, 2000), although occasionally different results in specific samples are found; e.g. Salanova and Schaufeli (2000) observed four factors in Spanish ICT workers. A systematic negative finding is that one particular cynicism item (item 13 (sic!), 'I just want to do my job and not be bothered') seems to be unsound (e.g. Schutte et al., 2000). Therefore, this item was deleted in the Dutch version of the MBIGS (Schaufeli \& Van Dierendonck, 2000). The three-factor structures of the original version as well as the general version seem to be invariant across countries (MBI-HSS: Enzmann, Schaufeli \& Girault, 1995; MBI-GS: Schutte et al., 2001) and occupations (MBI-ES: Byrne, 1991; MBI-GS: Leiter \& Schaufeli, 1996; Bakker, Demerouti \& Schaufeli, 2002).

Despite the fact that, from a psychometrical point of view, the MBI is a good tool for assessing burnout, a basic problem remains. Because of the absolute predominance of the MBI, the concept of burnout has been gradually equated with the way it is measured: burnout is what the MBI measures! Hence, the concept is narrowed to the three dimensions that are included in the MBI: exhaustion, cynicism (or depersonalisation), and reduced professional efficacy (or personal accomplishment). Although this common standard has the advantage that findings across studies can be compared straightforwardly, for instance by using meta-analyses, the narrow focus remains an issue. This is all the more serious since the MBI is neither grounded in firm clinical observation nor based on sound theorising. Instead, it has been developed inductively by factor-analysing a rather arbitrary set of items.

Clinical experience shows that burned-out employees who receive psychotherapeutic treatment report a host of distress complaints that are for a large part similar to those subsumed under the ICD-10 diagnostic label of neurasthenia (Schaufeli, Bakker, Schaap, Kladler \& Hoogduin, 2001). Depending on one's definition, such a-typical distress symptoms like sleep disturbance, inability to relax, irritability and tension headaches can either be considered elements of burnout, consequences of burnout, or accompanying symptoms. More specifically, clinical practice suggests that employees suffering from severe burnout are characterised by cognitive impairment, and report symptoms such as inability to concentrate, forgetfulness, and difficulties with solving complex tasks (Hoogduin, Schaap, Methorst, Peters
Van Neyenhof \& Van de Griendt, 2001). Such cognitive symptoms typically occur when one feels exhausted. Recently, Van Horn, Taris, Schaufeli and Schreurs (in press) developed an alternative exhaustion scale that was labelled 'cognitive weariness' and that includes items such as "I have trouble concentrating" and "I'm absent-minded". Their study among teachers showed that this scale was reliable and that it was substantively correlated with all MBI-burnout scales, but particularly with emotional exhaustion. Hence, based on clinical experience, the MBI-burnout concept should be supplemented by cognitive exhausting or weariness, and perhaps also with distress symptoms.

From a theoretical point of view one could argue that (emotional and cognitive) exhaustion and mental distancing (cynicism or depersonalisation) constitute the two key aspects of burnout. Exhaustion refers to the fact that the employee is incapable to perform because all energy has been drained, whereas mental distancing indicates that the employee is no longer willing to perform, because of an increased intolerance of any effort. Mental distancing - or psychological withdrawal from the task - can be seen as an adaptive mechanism to cope with excessive job demands and resulting feelings of exhaustion. However, when this coping strategy becomes a habitual pattern - as in cynicism or depersonalisation - it becomes dysfunctional because it disrupts adequate task performance. In its turn, job demands and exhaustion are further increased so that the vicious circle is closed. This view on burnout agrees with the way (occupational) fatigue is conceptualised, namely as the incapacity and unwillingness to maintain a particular performance level (Meijman \& Schaufeli, 1996). Essentially, incapacity and unwillingness to perform are considered as both sides of the same coin. Indeed, some empirical findings point to the central role of exhaustion and mental distancing as opposed to the third component, lack of professional efficacy. First, relatively low correlations of professional efficacy are observed with exhaustion and cynicism, whereas these two burnout dimensions are correlated relatively strongly (Lee \& Ashforth, 1996). In a similar vein, as we have seen above, both 'core of burnout' factors sometimes collapse into one factor (Green et al., 1991). Perhaps, however, this might reflect an artifact, because if all originally positively phrased MBI-professional efficacy items are rephrased negatively, correlations with exhaustion and depersonalisation increase substantially (Bouman, Te Brake \& Hoogstraten, 2002). This is a remarkable result that needs replication. Second, it seems that cynicism develops in response to exhaustion, whereas professional efficacy seems to develop independently and in parallel (Leiter, 1993). Third, professional efficacy is the weakest burnout dimension in terms of significant relationships with other variables (Lee \& Ashforth, 1996). Moreover, several scholars have argued that professional efficacy reflects a personality characteristic rather than a genuine burnout-component (Shirom, 1989; Cordes \& Dougherty, 1993).

Thus, from a theoretical point of view, (cognitive and emotional) exhaustion and mental distancing may be considered the core dimensions of burnout. Recently, an alternative burnout instrument has been developed - the Oldenburg Burnout Inventory (OLBI) - which includes both core dimensions of burnout that are labelled: exhaustion and disengagement (Demerouti, Bakker, Vardakou \& Kantas, 2002). The exhaustion scale includes items on the affective, physical and cognitive aspects of burnout, whereas the disengagement scale includes items that refer to distancing oneself form one's work. Unlike the MBI, the OLBI includes in each scale both positively and negatively worded items in order to avoid answering bias. A study on the convergent validity of the MBI and the OLBI, using multitrait-multimethod analyses showed that: (1) the latent variables representing both instruments are highly correlated and (2) all exhaustion and distancing/ disengagement items of both instruments load on the same 
single factor (Demerouti et al., 2002). These encouraging results suggest that the OLBI might be considered an alternative for the MBI-GS. To date, no other alternatives for assessing burnout in a standardised way are available. The second most often used burnout instrument - the Burnout Measure - is not suitable because it operationalizes only one core aspect of burnout exhaustion. Besides, this instrument suffers from some psychometric flaws (Enzmann, Schaufeli, Janssen \& Rozeman, 1998). Recently, a similar instrument was used in a series of studies by Shirom and Melamed (for an overview see Shirom, 2003). This so-called Shirom-Melamed Burnout Measure (SMBM) is based on the Conservation of Resources Theory and includes items that tap physical fatigue, emotional exhaustion, and cognitive weariness which represent the loss of three forms of individually possessed energy. Thus, like the BM, the S-MBM reduces burnout to mere exhaustion, albeit that it is measured in a rather differentiated way.

In sum: technically speaking, the MBI is a good instrument but from a clinical point of view its scope is rather limited and it should be supplemented by a scale that assesses cognitive weariness. Perhaps psychological distress symptoms should also be included, although it can be argued that rather than constituting burnout these are accompanying symptoms. Theoretically speaking, exhaustion (low energy) and mental distancing (poor identification) are the hallmarks of burnout that are not only assessed by the MBI but also by the OLBI, a recently developed alternative burnout instrument.

\section{Q: Is burnout limited to the human services?}

\section{A: No, burnout is not a typical helper syndrome}

As noted above, burnout was first observed in the human services. Maslach (1982), whose views have been very influential, considered burnout as a helper syndrome that results from emotionally demanding relationships with recipients of one's care. Such relationships are inherently difficult and upsetting because human services professionals deal with troubled people who suffer and are in need. As a result, these professionals are likely to feel emotionally exhausted, to treat their recipients like objects (depersonalisation), and to doubt their professional competence in working with recipients. So, according to Maslach (1982), the cause (emotional overload) as well as the symptoms of burnout (emotional exhaustion, depersonalisation, and lack of professional accomplishment) are typically found in those who do 'people work'. For that very reason, the initial version of the MBI was specifically geared towards this group of professionals that was intensively investigated. Schaufeli and Enzmann (1998, p. 72-73) calculated that the largest single occupational groups studied are teachers $(22 \%)$, nurses (17\%), and social workers (7\%). The fact that burnout was almost exclusively studied in human services professions reinforced the idea of burnout as a typical helper syndrome. Quite interestingly, and against expectations, an overview that compared the impact on burnout of 'helper' stressors (e.g. interaction with difficult people, confrontation with death and dying) versus more general job related stressors (e.g. workload, role conflict) lead Schaufeli and Enzmann (1998, p. 84) to conclude that: "...on empirical grounds, the assertion that burnout is particularly related to emotionally charges interactions with clients has to be refuted". So it seems that burnout is not a typical helper syndrome.

In fact, from the outset, many practitioners and prominent scholars have argued that burnout is not restricted to the human services (e.g. Golembiewski, Munzenrider \& Stevensen, 1986; Pines, Aronson \& Kafry, 1981). It has even been suggested that burnout may occur outside the occupational domain, as is illustrated by such terms as marriage burnout, athlete burnout, or parent burnout. Accordingly, there have been attempts to adapt the MBI for use outside the human services for such groups as small business owners (Boles et al., 2000), corporate employees (Evans \& Fischer, 1993), and managers (Cordes,
Dougherty \& Blum, 1997). However, most attempts were not successful; particularly, the depersonalisation scale proved to be a problem, since 'co-workers' is substituted for 'recipients' and as Garden (1987) has argued this changes the meaning of the items. This is exemplified by, Evans and Fischer (1993) who compared the factor structure of the MBI in a human services sample and a corporate sample. They conclude that their results "...cast doubt on the meaningfulness of the MBI depersonalization indicators as measures of a unitary construct in the private sector sample" (p. 34).

Since the introduction of the MBI-GS (see above) the three burnout dimensions can be measured independently from the professional context. That is, the exhaustion items are generic and refer to fatigue without direct reference to service recipients as its source; the cynicism items reflect a distant attitude towards one's work instead of the people one is working with; and the professional efficacy items encompass the non-social aspects of occupational accomplishments instead of exclusively focusing on the social aspects of these accomplishments. Hence, the MBI-GS has a broader scope than the original MBI. Or put reversibly, the original MBI dimensions can be seen as manifestations of a more general burnout symptomatology: that is, emotional exhaustion is a particular kind of exhaustion (namely caused by emotional demands), depersonalisation is a particular kind of cynicism (namely directed towards recipients), and personal accomplishment is a particular kind of professional efficacy (namely in relation to recipients).

An advantage is that the MBI-GS, can be used both in human services and non-human services samples, so that they can be directly compared. For instance, Taris, Schreurs and Schaufeli (1999) showed that, psychometrically speaking, the MBI-GS performed equally well in a sample of software engineers as among university teaching staff, but that levels of exhaustion and cynicism were significantly higher in the former sample compared to the latter, whereas the reverse was true for professional efficacy. In addition, their theoretical model fitted equally well across both samples: exhaustion was predicted by job demands and lack of decision latitude, whilst cynicism and professional efficacy were predicted by lack of decision authority and lack of skill discretion. In other words, the study of Taris et al. (1999) shows that the MBI-GS can be used to measure burnout among educators and corporate employees and that - despite differences in levels - burnout is predicted by similar variables in both samples. By the way, this is another indication that burnout is not a typical helper syndrome. Other studies, using the MBI-GS have also demonstrated the consistency of the burnout construct across human survives and non-human services samples (e.g. Leiter \& Schaufeli, 1996; Bakker, Demerouti \& Schaufeli, 2002).

In sum: burnout is not a typical helper syndrome that exclusively occurs in the human services. This inaccurate belief stems from the fact that, initially, burnout was studied almost exclusively among human services professions because the dominant assessment tool - the original version of the MBI - was specifically tailored to this type of employees. More recent studies with the general MBI version confirm its sound psychometrical characteristics and show similar results across human services and non-human services samples.

\section{Q: Is burnout a mental disorder?}

A: Yes, and it can be discriminated from other syndromes Instead of answering the question whether burnout is a mental disorder affirmative it is better to realize that the answer depends on one's perspective. Basically, as noted before, there are two perspectives on this issue. First, the social psychological view as advocated by Christina Maslach that conceptualises burnout as a continuous variable that is measured by the MBI. Although the MBI test manual provides cut-off points to discriminate between 'low' (lower third), 'average' (middle third) 
and 'high' (upper third) levels of burnout, the authors warn that this coding should not be used for individual diagnostic purposes, because: "...there is insufficient research on the pattern(s) of scores as indicators of individual dysfunction or the need for intervention" (Maslach, Leiter \& Jackson, 1996; p. 9). In fact, the MBI is designed for use at group level and not at individual level. Second, the clinical view as advocated by Herbert Freudenberger considers burnout a dichotomous variable that is either present or absent; someone is a burnout 'case' or not. These views coincide with the distinction that Paine (1982) made between 'Burnout Stress Syndrome' and 'Burnout Mental Disability', respectively. The former refers to a mild form of unwell-being that does not prevent the employee to do his or her job, whereas the latter is described as “... a serious clinically relevant pattern of personal distress and diminished performances which is an end state of the burnout process" (p.6). Recently, Brenninkmeijer and Van Yperen (2003) discuss the pros and cons of using burnout as a continuous variable and as a dichotomous variable.

Virtually all burnout research has been conducted among relatively healthy employees, whilst those who are not working because they are ill, disabled, or left the organisation are usually not sampled. In other words, burnout research suffers from the so-called healthy worker effect, a systematic bias because only working - and thus relatively healthy - employees are researched. Or put differently, so far burnout has only been studied as stress syndrome and not as mental disability. However, there is more and more pressure building up from practitioners who deal with severe burnout to develop valid assessment tools, particularly in countries like The Netherlands, where 'burned out' and 'overstrained' employees enter the social welfare and health care systems in great numbers.

Can burnout be discriminated from other mental disorders? The issue of 'old wine in new bottles' has haunted the concept of burnout from the very beginning. It has been suggested especially by psychiatrists, occupational physicians, and clinical psychologists - that burnout is a 'mere' depression or 'just' another name for an adjustment disorder. However, mounting evidence from practice suggests that this is not the case. For instance, based on their clinical experience Hoogduin et al. (2001) argue that burnout can be differentiated diagnostically from adjustment disorder, mood disorder, anxiety disorder, and from the chronic fatigue. Hence, Hoogduin (2001) proposed a decision tree that guides the clinician through the diagnostic process and assists in differentiating between burnout and these other mental disorders. In a somewhat similar vein, in 2000 the Royal Dutch Medical Association has issued guidelines to be used by general practitioners and occupational physicians for diagnosing 'stress related disorders' (see: http://www.richtlijnennvab.nl/richtlijnen_frameset.html). Three types of such disorders are distinguished that reflect progressive impairment: 'distress', 'overstrain' and 'burnout', respectively. Hence, these guidelines - according to which Dutch physicians are currently trained - agree with Paine (1982), who regarded 'burnout' as a mental disorder, being the end-state of a process. The Dutch diagnostic guidelines include the use of the MBI as an individual assessment tool because in the Netherlands clinically validated cut-off points have been developed that can be used to discriminate burned out cases from non-burned out cases (Brenninkmeier \& Van Yperen, 1999; Schaufeli et al., 2001). It should be warned, however, not to use such cut-off scores in other countries because this can lead to serious misinterpretations as has been demonstrated by Schaufeli and Van Dierendonck (1995).

As far as research on the discriminant validity of burnout visà-vis depression is concerned, Glass and McKnight (1996, p. 33) concluded from their review of over eighteen studies that "Burnout and depressive symptomatology are not simply two terms for the same dysphoric state". Both are related because mood symptoms play a major role, but they are not redundant concepts. Not only do the symptoms of burnout and depression differ, but there seem to be different psychological processes involved as well. For instance, burnout - at least initially - is limited to the occupational domain, whereas depression is context-free (Demerouti, Bakker, Nacheiner \& Schaufeli, 2000); more particularly, a lack of reciprocity in the relationship with one's partner predicts depression (and not burnout), whereas a lack of reciprocity in the relationship with recipients at work predicts burnout (and not depression) (Bakker, Schaufeli, Demerouti, Janssen, Van der Hulst \& Brouwer, 2000a).

In sum: to date, most research focused on basically healthy employees, thereby neglecting those who suffer from severe burnout. Potentially, the MBI can be used for assessing individual burnout levels, provided that clinically validated cut-offs exist, like in the Netherlands. Burnout can be considered a mental disorder that may be differentiated clinically as well as empirically from other mental disorders, most notably depression. This conclusion has important practical and political implications because it follows that 'burnout' should have official status in the sense that it is recognised as a legitimate reason for sickness absenteeism or work disablement. To my knowledge this is only (partly) the case in The Netherlands.

\section{Q: What is the prevalence of burnout?}

A: About 4\%-7\% of the working population, amounting to about $10 \%$ in specific occupations

Once burnout is assessed as a dichotomous variable that is based on a clinically validated cut-off score, it is basically possible to estimate its prevalence. Yet, another requirement has to be met: the sample under study should be representative and sufficiently large. Unfortunately, this is only very seldom the case. In fact, despite claims that burnout is endemic, only very limited knowledge exists about its prevalence. Epidemiological studies that suffice both criteria - validated cut-off and large, representative sample - are virtually lacking. Instead, we have to rely on representative samples of single professional groups, or on heterogeneous composite samples of unknown representativeness. For instance, it appeared that 9,7\% and $13,9 \%$ of a the same representative sample of Dutch primary and secondary school teachers suffered from severe ('clinical') burnout in $1996(N=1,309)$ and in $1997(N=998)$, respectively (Taris, Schaufeli, Schreurs \& Caljé, 2000). Interestingly, twothirds of the teachers were burned-out at both occasions, whereas only one-third recovered within one year, which illustrates the chronic nature of burnout. Furthermore, older, male, secondary school teachers with full-time contracts ran a significantly higher risk compared to younger, female, primary school teachers with part-time contracts. Bakker, Schaufeli and Van Dierendonck (2001b) summarised the prevalence of burnout in several representative Dutch occupational samples: occupational physicians, $11,3 \%(N=760)$, general practitioners, $8,2 \%(N=562)$, community nurses, $7,8 \%(N=116)$, midwifes, $6,6 \%(N=316)$, physiotherapists, $5,4 \%(N=444)$, dentists, 4,7 $(N=708)$, oncology nurses $1,7 \%(N=410)$. The highest rate was found among volunteers, who care around the clock for their mentally disturbed relatives, family members or friends, $13,9 \%$ $(N=108)$. Across the entire MBI-HSS/ES database of 13,463 human services professionals - that also includes many nonrepresentative samples - $4 \%$ appeared to suffer from clinical burnout. Another $16,1 \%$ was believed to be at risk for burnout: that is, they scored in the upper quartile of the distribution of two of the three MBI-scales.

Using the MBI-GS in a national representative sample of the Dutch working population $(N=1,129)$, Zijlstra and De Vries (2001) estimated that 7,2\% suffered from clinical burnout. The highest rates were found in commerce, hotel and catering industry $(12,2 \%)$ and in teaching $(9 \%)$, whereas the lowest rates were found in the commercial services $(5,4 \%)$ and public governance $(5,4 \%)$, with the human services $(6,8 \%)$ and 
manufacturing $(6,5 \%)$ somewhere in between. No differences were observed between males and females, but older, more experienced, single workers who experienced a high workload were significantly more at risk compared to younger, less experienced, married workers who experienced a low workload.

So far, I only presented data from the Netherlands because only for this country clinically validated cut-off scores are available. But what if we compare burnout scores from the Netherlands to the USA, for example? Do the levels of burnout differ between both countries? Schaufeli and Enzmann (1998, p. 60-62) compared data from 57 US studies (total $N=12,239$ ) with 27 Dutch studies (total $N=10,502$ ) and showed that levels of emotional exhaustion and depersonalisation are significantly higher in the US than in the Netherlands, whereas reduced personal accomplishment is significantly lower. So, on both core dimensions of burnout Americans score less favourably, which agrees with several other European studies, as Schaufeli and Enzmann (1998, p. 62) concluded. The cause of this systematic difference is still unclear; it might be due to such factors as answering bias, cultural differences, different labour relations, or different working conditions.

In sum: mainly based on secondary analyses of Dutch data, it is estimated that about $4 \%-7 \%$ of the working population suffers from severe or clinical burnout. For the Netherlands this means between 250,000 and 440,000 employees. A recent epidemiological study on mental disorders in the Dutch working population (Laitinen-Krispijn \& Bijl, 2000) showed that the prevalence of three most frequently encountered DSM-II-R diagnoses - major depressive disorder $(4,8 \%)$, simple phobia $(5,6 \%)$, and alcohol abuse $(4,4 \%)$ - are within the same range as the estimated burnout prevalence. In some professional groups, however, such as physicians and teachers burnout rates are much higher, amounting to about $10 \%$. It should be kept in mind that because of the healthy worker effect these rates are inflated and most likely represent an underestimation of the true number of burnout cases in the working population.

\section{Q: Is burnout a global phenomenon?}

\section{A: Yes, it looks like that}

Since the early 1990s burnout research spawned across the globe. In their book "Global burnout: A worldwide pandemic explored by the phase model", Golembiewski, Boudreau, Munzenrider and Luo (1996) counted 34 counties outside the USA where burnout research had been carried out. Meanwhile this number has certainly grown. Indeed, there is no a priori reason why the experience of burnout should be restricted to a particular country or cultural setting, all the more because the organisation of work undergoes similar sweeping changes across the globe, especially in the developing countries (Landsbergis, 2003). Yet, a truly cross-cultural perspective on burnout is virtually lacking and burnout researchers have been accused of ethnocentrism because they merely seek to replicate research findings in other countries and cultures that were previously obtained in the US and in Europe (Rösing, 2003).

Two lines of cross-cultural research on burnout can be distinguished. First, psychometric research that tests the equivalence of the MBI across different countries and cultures. Generally speaking, results confirm the positive psychometric properties of the MBI, also outside English speaking countries (see above). Secondly, descriptive research that studies the relationship of burnout with a similar set of other variables across countries. For instance, Golembiewski et al. (1996) validated their so-called phase model of burnout in over a dozen countries by relating their eight progressive phases of burnout to a host of workplace, health and performance variables. They conclude that 'burnout seems to be generic and culture specific' (p. 236) which means that, generally speaking, their phase model is supported across nations, but nevertheless some differences remain. Instead of testing a priori formulated hypotheses that pertain to specific cultural differences,
Golembiewski and his colleagues seek to replicate a model that has been developed in the US. The differences found between countries are interpreted post hoc, using cross-cultural notions such as individualistic and collectivistic cultural orientations. The results obtained by Golembiewski et al. (1996) as well as by others (e.g. Schaufeli \& Janzcur, 1994) confirm that the similarities of research findings across different countries are larger than the dissimilarities. This is also demonstrated by Schaufeli and Enzmann (1998, pp. 63-65) who observed that despite differences in levels of burnout between the US and The Netherlands (see above), strong similarities in occupation specific burnout profiles exist. For instance, in both countries teachers have the highest levels of exhaustion, and law enforcement personnel reports the highest level of depersonalisation, and reduced personal accomplishment is most common in the social services. Recently, Savicki (2002) used Hofstede's well-know cultural dimensions in a study on child and youth-care workers in thirteen different countries. He observed, for instance, that masculine cultures that emphasized the value of work and career as an integral part of it's members identities produced higher levels of burnout (exhaustion and depersonalization), whereas cultures low in power distance that typically value approachable leaders who exert their influence via consultation produce less burnout (higher levels of accomplishment).

In sum: although burnout is studied around the globe - using the same cross-nationally validated MBI to assess levels of burnout - a truly cross-cultural perspective is still lacking. The same applies for systematic cross-national epidemiological research on the prevalence of burnout, as was noted before (see Q 4). Descriptive research in many countries shows that, by and large, similar variables are related to burnout. Nevertheless, some differences also seem to exist which might reflect different national or cultural orientations. There seems to be a relationship between general cultural dimensions and levels of burnout, at least in a specific occupational sample of child and youth care workers.

\section{Q: Is burnout relevant for organisations?}

A: Yes, but only to a limited degree

From the onset, it has been claimed that burnout not only is detrimental for the individual but likewise for the organisation since it would foster absenteeism, job turnover, poor quantitative and qualitative performance, and loss of productivity and efficiency. These negative organisational consequences of burnout have in common that they all - directly or indirectly - lead to financial losses. For instance, when burned out employees are on sick leave or become work incapacitated, employers - at least in some countries - have to pay part of their benefits; when employees leave the organisation new personnel has to be hired and trained; when the quality of services is poor customers go away and market share is lost; and when the productivity and efficiency decreases profits decrease likewise. Hence, it is argued, employee burnout is potentially an economic loss for organisations. This line of reasoning is generally used by organisational consultants and researchers for alerting management and pointing to the necessity to prevent burnout. The message they want to bring across is that preventing burnout pays off, not only psychologically in terms of increased worker well-being, but also economically in terms of a better earnings.

But in how far is the assertion that employee burnout is linked to economically relevant organisational behaviours supported by empirical evidence? This is a rather complex issue because it involves the relationship between subjective (burnout) and objective (observable behaviour) variables, and because in many instances the relevant behaviours (e.g. performance, efficiency, and productivity) can only be measured at group level. Because of this complex nature the relationship between burnout and organisational behaviour has been under-researched, particularly given its obvious relevance for organisational practice. 
So far, particularly absenteeism, job turnover and impaired performance have been studied in relation to burnout and, unfortunately, results are not very impressive. Schaufeli and Enzmann (1998, pp. 91-93) identified twenty-seven studies that relate burnout to these three types of organisational behaviours and concluded for absenteeism: "...despite the popular assumption that burnout causes absenteeism, the effect is rather small and is most related to emotional exhaustion" (p. 91). Typically, correlations between (registered) absenteeism and exhaustion do not exceed 0,15. Furthermore, in contrast to studies on intention to leave that generally show relatively strong correlations with burnout (typically between 0,35 and 0,45 for exhaustion and cynicism), relations with actual turnover are much weaker (maximum correlations about $0,20)$. This suggests that a large proportion of burned out employees stays in their job involuntarily, most likely because they are 'locked in'. But do those burned out employees perform less well? Again, the conclusion is disappointing. For self-rated performance, correlations are relatively high (typically, between $-0,20$ and $-0,25$ ) compared to correlations with objective performance indicators that do not exceed 0,10. However, according to Schaufeli and Enzmann (1998, p. 92) the number of studies that found the expected negative correlation (i.e. 4) is about just as high as the number of studies that did not find a significant relationship (i.e. 3). Quite interestingly, one study found an opposite positive relation between burnout and performance: the more burned out intensive care nurses were, the sooner the patients left the ward (Schaufeli, Keijsers \& Reis-Miranda, 1995). This lead Schaufeli and Enzmann (1998, p. 93) to the conclusion that: "...in contrast to the prevailing view, burnout is not necessarily linked to low levels of actual performance".

What about more recent studies that appeared after the review of Schaufeli and Enzmann dated 1998? Do they change this somewhat disappointing picture? Although some recent studies found slightly higher correlations with registered absenteeism ranging from about 0,19 to 0,38 (Iverson, Olekalns \& Erwin, 1998; Van Dierendonck \& Mevissen, 2002) - the association remains rather weak. That does not mean that the practical relevance of burnout for absenteeism is negligible, though. For instance, Taris, Schaufeli, Schreurs and Caljé (2000) observed that $30 \%$ of the teachers who have been diagnosed as 'clinically burnout' report ill in the following year, against only $8 \%$ who did not received this diagnosis. In terms of financial losses this makes quite a difference.

As in previous research, relationships of burnout are much stronger with the intention to leave (e.g. Harrington, Bean, Pintello \& Matthews, 2001) than with actual job turnover (e.g. Prosser et al., 1999). However, occasionally, a somewhat stronger relationship is found with the latter as well. For instance, Ross, Greenfield and Bennett (2000) observed that AIDS volunteers with high levels of depersonalisation were over $30 \%$ more likely to drop out within two years compared to those with lower depersonalisation scores. Again, like with absenteeism, such an increased probability is of high practical significance.

Finally, recent research confirms the weak relationship between burnout (exhaustion) and performance. For instance, Leiter, Harvey and Frizzell (1998) showed that patient satisfaction with nursing care was negatively associated with nurses' levels of emotional exhaustion but - quite surprisingly - not with depersonalisation. Recently, these findings were replicated on the team level: in teams with many nurses who suffered form exhaustion, patients were less satisfied with nursing, whereas no such effects were found for depersonalisation (Garman, Corrigan \& Morris, 2002). Interestingly, a recent study among frontline employees in service organisations found that with increasing burnout these employees were able to maintain their productivity levels while the quality of their services deteriorated (Sing, 2000). The latter agrees with both previously mentioned studies on patient satisfaction.
Burnout may also be relevant for organisations in another way, namely when it is associated with objective work characteristics that can potentially be changed by management. Although such studies are rare some fine recent examples exist that document that burnout is indeed related to such objective characteristics. For instance, Taris, Stoffelsen, Bakker, Schaufeli and Van Dierendonck (2002) asked eight independent experts to rate the levels of job autonomy of 28 different professions and found that these expert-ratings, which showed high inter-rater reliability, were negatively related to burnout: those professions with the lowest levels of autonomy included most professionals with high burnout scores. Even more impressive is the finding that in US hospitals the patient-to-nurse ratio is linearly related to nurses' levels of burnout; that is, each additional patient per nurse is associated with a $23 \%$ increase in the odds of burnout (Aiken, Clarke, Sloane, Sochalski \& Silber, 2002). Both examples provide a clear indication of the relevance of burnout for organisations since they show that burnout levels may be decreased by increasing job autonomy and by decreasing workload (i.e. lowering the patient-to-nurse ratio by hiring more nurses).

In sum: although strictly speaking the relationships between burnout and economically costly negative employee behaviours (absenteeism, job turnover, poor performance) are neither consistent nor strong, some indications exist that such a relationship does exists, at least to some degree. Despite this rather disappointing scientific result, the practical relevance of such weak relationships is considerable in economic terms. In addition, recent evidence suggests that objective work characteristics (i.e. job autonomy, workload) that can be influenced by management are related to burnout, which offers possibilities for primary prevention of burnout in organisations.

\section{Q: What are the causes of burnout?}

\section{A: Most likely, perceived work overload, role problems and lack} of support

Compared to the number of cross-sectional studies on burnout, the number of longitudinal investigations is relatively small. This means that a lot is known about variables that are related to burnout, but that relatively little is known about its causes or consequences. It is commonplace that authors of cross-sectional investigations write in the concluding section that longitudinal research is needed in order to disentangle cause and effect. From cross-sectional research we know that burnout is particularly related to experienced qualitative and quantitative work overload, role problems (role ambiguity and role conflict), lack of social support (from colleagues and supervisors), and lacking self regulatory job characteristics (feedback, autonomy, participation in decision making) (for reviews see: Lee \& Ashforth, 1996; Schaufeli \& Enzmann, 1998; Maslach, Schaufeli \& Leiter, 2001; Schaufeli \& Buunk, 2002). But do they also cause burnout? Schaufeli and Enzmann (1998) identified only eight sound longitudinal studies; that is, studies that measured the causal variables as well as burnout at every point in time, and controlled for prior levels of burnout. Methodologically speaking, such studies may uncover what factors predict changes in burnout across time. After reviewing these eight studies in detail they concluded that these studies: "...could not reproduce the results found in cross-sectional studies. Either longitudinal effects were very small or not significant, or, contrary to expectations and despite positive cross-sectional correlations demands seems to be associated negatively with burnout" (p. 95). It should be noted that this conclusion is based on a rather rigorous selection of the most sophisticated longitudinal studies. Less sophisticated studies that do not control for previous levels of burnout reveal positive longitudinal relationships of burnout with previous levels of work overload, role problems and lack of social support (e.g. Burke, Greenglass \& Schwarzer, 1996; Prossner et al., 1999; Low, Cravens, Grant \& Moncrief, 2001).

And what about more recent longitudinal studies? Do they change this rather gloomy picture? As before, sophisticated longitudinal studies remain very rare and their results are 
likewise disappointing. For instance, a rather innovative sevenwave longitudinal study of Burisch (2002) that followed German student-nurses for the first three years of their careers perfectly illustrates the fact that cross-sectional relations between burnout and various predictors (e.g., workload, role conflicts, lack of decision latitude) could not be replicated longitudinally, despite the use of various different ways of data-analyses. Burisch (2002, p. 15) concludes, pitifully: " ...attempts at predicting change in burnout scores turned out to be unsuccessful, despite several features of the present investigation that had raised hopes to the contrary".

How can these disappointing longitudinal results be explained? It is plausible that methodological problems play a large role. For instance, cross-sectional correlations between burnout and job characteristics might be spuriously high because of a common 'third variable', such as negative affectivity, which is less likely to play that role across time. Perhaps even more important is the fact that burnout appears to be very stable across time; roughly $60 \%$ of the variance in burnout after one year is explained by initial levels of burnout. Even after very long periods of time, burnout levels tend to be stable; for instance, after five years stability coefficients of burnout ranged from 0,47 to 0,65 (Bakker, Schaufeli, Sixma, Bosveld \& Van Dierendonck, 2000c) and the stability coefficient of exhaustion after eight years is 0,44 (Toppinen-Tanner, Kalimo \& Mutanen, 2002). Practically speaking this means that current levels of burnout are largely predicted by previous levels of burnout. Hence, controlling for previous burnout levels leaves almost no 'room' for the impact of other predictor variables. The fact that burnout is stable across time does not necessarily mean, however, that mean levels of burnout remain the same. This is because statistically speaking stability (which is based on correlations) is independent of change (which is based on mean scores). For instance, Etzion (2003) showed that after annual vacation levels of burnout decreased, whereas this was not the case for a comparison group that had not been on holiday.

In sum: when a rigorous selection is made of longitudinal studies that assess the effects of antecedents on changes in burnout levels, virtually no causal effects are found. Most likely, this is because burnout appears to be very stable across time. This does not mean, however, that over time mean levels of burnout remain the same. According to longitudinal studies that do not control for prior levels of burnout, work overload, role problems and lack of social support may be considered antecedents.

\section{Q: What are the consequences of burnout?}

A: Common infections, distress, depression, job dissatisfaction, absenteeism, job turnover, and poor performance

A similar picture as with the causes of burnout emerges when it comes to its consequences. Likewise, only a longitudinal design may uncover the consequences of burnout, whereas most studies use a cross-sectional design. Three types of possible consequences of burnout have been studied: ill-health, negative job attitudes, and impaired organisational behaviour (for a review see Schaufeli \& Enzmann, 1998, pp. 86-93). Crosssectional studies show that burnout is related to such indicators of ill health as depression, psychosomatic complaints, distress, and physical health problems. As we have seen before (Q1), it is debatable whether or not psychosomatic complaints and distress are possible consequences or concomitants of burnout. As noted before, clinical evidence favours the latter point of view. In addition, impressive cross-sectional evidence exists on the relationship of burnout with such job attitudes as job dissatisfaction, poor organisational commitment and intention to quit. Finally, as shown before (Q6), some indications were found that burnout is related to impaired organisational behaviour (absenteeism, job turnover and poor performance).

But what about longitudinal evidence for a causal relationship between burnout and these probable consequences? Virtually no longitudinal studies exist on the health consequences of burnout, with at least three notable exceptions. McKnight and Glass (1995) tried to answer the question whether depression is a cause or a consequence of burnout but they did not come up with a clear answer. Instead, it seemed that depression can act as a cause as well as the consequence of burnout. A similar result was recently obtained in a longitudinal study among UK doctors with distress, as measured with the General Health Questionnaire: distress increased exhaustion, which, in its turn, increased distress (McManus, Winder \& Gordon, 2002). Recently, a prospective cohort study among over 12,000 Dutch employees showed that burnout, and particularly exhaustion, predicted the occurrence of common infections such as gastroenteritis, common cold, and flu-like illness (Mohren, Swaen, Kant, van Amelsvoort, Born \& Galama, in press). Finally, it appeared among medical residents that were followed four times across one year, that burnout levels at previous occasions were predictive of depression, poor general health and impaired clinical skills (Hillhouse, Adler \& Walters, 2000). However, the authors did not control for earlier levels of burnout.

As far as negative job attitudes are concerned, a similar picture emerges: virtually no longitudinal studies exist with one exception that suggests that burnout causes diminished job satisfaction instead of the other way around (Wolpin, Burke \& Greenglass, 1991). As described above (Q5), burnout leads to absenteeism and job turnover, and probably to poor performance although the longitudinal relations are rather weak.

There is another interesting type of longitudinal research that focuses on the internal dynamic of the burnout process itself. That is, the sequence of burnout symptoms is studied. Traditionally, two different points of view exist. Leiter and Maslach (1988) argue that exhaustion leads to detachment, which is to be seen as a dysfunctional way of coping with fatigue because it impairs performance and leads to feelings of reduced accomplishment. On the other hand, Golembiewski and his colleagues argue that the burnout process starts with depersonalisation, which is followed by exhaustion and reduced personal accomplishment, respectively (Golembiewski, Munzenrider \& Stevenson, 1986). Both competing models were examined by Lee and Ashforth (1993) and they found - using a longitudinal design - that the model of Leiter and Maslach fitted slightly better to the data than that of Golembiewski et al. This result was corroborated by Van Dierendonck, Schaufeli and Buunk (2001), who, based on a secondary analysis of longitudinal data, also tested a third sequential model that fitted even better to the data than the model of Leiter and Maslach (1988): reduced personal accomplishment $\rightarrow$ depersonalisation $\rightarrow$ emotional exhaustion. The authors argue that professional competence (personal accomplishment) is a crucial resource which - when lacking - fosters an inadequate way to deal with recipients (depersonalisation) which ultimately leads to feelings of exhaustion. Recently, Taris, Le Blanc, Schaufeli and Schreurs (2003) compared the fit of the previous three sequential models to the data of two independent samples and found that the model of Maslach and Leiter (1988) fitted best, at least crosssectionally. However, this result was not replicated longitudinally: neither sequential model fitted to the longitudinal data. In addition, no support was found for depersonalization as an effective coping strategy. Instead of reducing job demands at a later point in time, high levels of depersonalization increased the perceived job demands. Although, longitudinal results on the sequence of burnout symptoms are equivocal, most cross-sectional studies particularly those that use structural equation modeling assume that exhaustion 'leads to' depersonalisation or cynicism, whereas personal accomplishment or professional efficacy is assumed to develop in parallel (e.g. Bakker et al., 2001c; Toppinen-Tanner et al., 2002)

In sum: like research on the antecedents, longitudinal research on the consequences of burnout is very scarce. Some indications are found that burnout may lead to ill-health (i.e., common 
infections, depression, distress), negative job attitudes (i.e., job dissatisfaction), and impaired organisational behaviour (i.e., absenteeism, job turnover, poor performance). In case of depression and distress, reversed causation was observed as well. Furthermore, research on the sequence of occurrence of burnout symptoms has produced equivocal results.

\section{Q: How can burnout be explained?}

A: By a multitude of theories and models at various levels of aggregation, of which only a few are supported by ample empirical results, most notably social exchange theory

Since burnout is a complex, multi-causal process that involves various factors at different levels of aggregation there is no overarching, all encompassing theory of burnout, and most likely there never will be. This means that one has to choose a particular preferred aggregation level. Basically, four such levels can be distinguished that each include a number of theoretical approaches. In their overview Schaufeli and Enzmann (1998, pp. 101-142) distinguish between individual approaches, interpersonal approaches, organizational approaches, and societal approaches that include eight, five, three, and three different theoretical perspectives, respectively. In fact, a physiological perspective should be added, albeit that psychophysiological knowledge on burnout is still virtually absent. The choice for a particular aggregation level for explaining burnout depends on one's purpose. For instance, a psychotherapist is likely to focus on the individual level, whereas an organisational consultant is more interested in understanding burnout at the organisational level. At any rate, rather than pointing to common ground this myriad of different approaches strikes one as being kaleidoscopic. How to discriminate between all these different approaches; which ones are more valid and which ones less? Although it is, of course, legitimate to theorise about burnout without putting one's theoretical ideas to a test or to illustrate one's theoretical ideas with just a few case studies, I prefer to take the amount and the consistency of quantitative empirical support as an indicator of the extent to which a particular theory is valid.

It appears that virtually all individual approaches to burnout lack quantitative empirical support. In fact, these approaches have not been tested as such, but were formulated post-hoc. Interpersonal approaches to burnout are, generally speaking, better empirically supported. The traditional approach of Maslach (1982) that considers emotional overload as the root cause of burnout is supported by empirical results, but as indicated above recipient related stressors (e.g. interaction with difficult people, confrontation with death and dying) are less strongly related to burnout than more general job related stressors (e.g. workload, role conflict). Hence, contrary to Maslach's (1982) assumptions, emotional overload is not a specific cause of burnout, which casts serious doubts on the assertion of burnout as helper syndrome (see Q2). Besides, Maslach (1982) does not explain why such emotionally charged relationships with recipients are so stressful. This question has been taken up by me and my colleagues, assuming that, psychologically speaking, lacking reciprocity is the driving force behind stressful interpersonal relationships at work (see Schaufeli \& Enzmann, 1998, pp. 119-122 and Schaufeli, 2003). Put simply: burned out employees invested too long, too much in their relationships with others without receiving enough back in return from them. It is this so-called negative social exchange relationship that makes helper jobs so stressful and causes emotional overload. Indeed, it appeared from a series of studies that lack of interpersonal reciprocity is related to burnout in such occupational groups as (student) nurses, general practitioners, hospital doctors, police officers, primary and secondary school teachers, staff working with the mentally handicapped, and correctional officers (for an overview see Buunk and Schaufeli, 1999; Schaufeli, 2003). Not only crosssectional but also longitudinal relationships have been found between interpersonal reciprocity and burnout (e.g. Bakker et al., 2000c; Taris, Peeters, Le Blanc, Schreurs \& Schaufeli, 2001;
Van Dierendonck, Schaufeli \& Buunk, 2001). In addition, it appears that the social exchange relationship of the employee with the organisation is associated with burnout as well: when employees feel that they invest too much in the relationship with the organisation they work for, compared to the (im)material benefits they receive from that organisation, they are likely to experience burnout. Finally, as similar social exchange principles govern the relationships within teams, lack of reciprocity at team level is also likely to contribute to burnout. Accordingly, energy draining negative social exchange relationships at interpersonal level as well as organisational level and team level are associated with burnout. A suchlike multilevel social exchange model was successfully tested among student nurses, teachers, therapists form a forensic psychiatric clinic, mental health workers, and police officers (for an overview see Schaufeli, 2003).

Whereas a negative social exchange relationship - or lack of reciprocity - is likely to play a role in the emergence of burnout, other social psychological processes such as social comparison (e.g., Buunk, Ybema, Van der Zee, Schaufeli \& Gibbons, 2001) and emotional contagion (e.g., Bakker \& Schaufeli, 2000) seem to play a role in perpetuating burnout in work groups.

Organisational approaches to burnout are usually descriptive in nature. That is, instead of explaining burnout they describe what type of organisational variables are related to burnout (see Schaufeli \& Enzmann, 1998, pp. 124-135). Such heuristic models have received some - largely cross-sectional - empirical support (e.g., Golembiewski, Boudreau, Munzenrider \& Luo, 1996). An exception has to be made for the recently developed Job DemandResources model that assumes that two underlying psychological processes play a role in burnout: an effort-driven process in which excessive job demands lead to exhaustion and a motivation-driven process in which lacking resources lead to disengagement (Demerouti, Bakker, Nachreiner \& Schaufeli, 2001).

Like individual approaches, societal approaches that emphasise the role of structural and cultural determinants of burnout have received little or no empirical support (see Schaufeli \& Enzmann, 1998, pp. 135-139). Nevertheless, it is important to realise that burnout is not only a subjective individual experience, but that it is also rooted in society and contemporary culture (Rösing, in press).

In sum: instead of a single theory on burnout there are many theoretical explanations that cover different aggregation levels and include mainly individual, interpersonal, and organisational approaches, of which only few have received empirical support. It seems that social psychological approaches are most successful in uncovering the underlying psychological processes that cause and maintain burnout. Lack of reciprocity at the interpersonal as well as the organisational level seems to play a crucial role in this respect.

\section{Q: Are burnout interventions effective?}

A: Individual or group based interventions (workshops) seem to be effective, particularly in reducing exhaustion in the short run. Evidence for long-term effects and for the effectiveness of organisation based interventions is still very weak

As indicated in the brief historical sketch above, interventions to reduce burnout always have been popular. However, so far, no general recipe has emerged for combating burnout, which is not surprising given its complex nature. Instead, the past quarter of a century witnessed a booming, largely commercial antiburnout business, that used numerous approaches which are claimed to be effective. Schaufeli and Enzmann (1998, pp. 143183) described over thirty approaches and classified them according to their focus (individual, individual-organisational interface, organisation) and their purpose (identification, primary prevention, secondary prevention, treatment, rehabilitation). For instance, relaxation is an individual, secondary preventive approach targeted at the group at risk, 
whereas job redesign is an organisational, primary preventive approach targeted at all employees. So-called burnout workshops combine various approaches, they usually include self-assessment, didactic stress management, relaxation, cognitive and behavioural techniques, time management, promotion of a more realistic image of the job, and peer support. Basically, such workshops rest on two pillars: increasing the participant's awareness of their work-related problems and enhancing their coping resources by skills training and providing social support.

What can be concluded from the overview of Schaufeli and Enzmann (1998)? First, most interventions are rather general instead of being specifically tailored to reduce burnout (e.g. time management, job redesign, management development). Second, the focus of most interventions is biased towards the individual, whereas organisational based interventions are rather scarce, despite the relevance of job characteristics for the development of burnout. Third, there are only very few well-designed studies that document the effectiveness of burnout interventions, usually burnout workshops. Fourth, and most importantly, these studies show that the core affective symptom of burnout - exhaustion - can by reduced by training employees to use particular coping skills, notably relaxation and cognitive restructuring. On the other hand, cynicism and reduced professional efficacy seem rather resistant to change, which is not so surprising since most techniques that are employed in those burnout workshops are aimed at reducing negative arousal and not at changing attitudes (cynicism) or enhancing professional skills or resources (efficacy)

Are these conclusions of Schaufeli and Enzmann (1998) still valid or has the picture changed, particularly as far as the effectiveness of interventions is concerned? As the next examples illustrate, the general picture still holds today. Recently, Van der Klink, Blonk, Schene and Van Dijk (2001) performed a meta-analysis of almost fifty (quasi-)experimental studies on the effectiveness of interventions for work related stress (including burnout, overstrain, and distress) and they found - in terms of effect-size - 'medium' effects for cognitivebehavioural programmes and 'small' effects for relaxation programmes. In contrast, workplace interventions showed no significant effects. Such interventions are not only scarce (only 5 were detected in the meta-study), but they are also notoriously difficult to evaluate because instead of individuals or groups, organisations constitute the level of analysis. The same authors also evaluated the effectiveness of an activating intervention to reduce sickness absenteeism for employees who suffered from overstrain (Van der Klink et al., in press). Their intervention was carried out by occupational physicians who received a three-day training course. The programme consisted of three stages: (1) understanding the origin of the current problems; (2) identification of stressors and training of problem solving skills; (3) putting these skills into practice. Results showed that, at three months significantly more patients in the intervention group had returned to work compared to the control group, that received 'care as usual'. At twelve months all patients returned to work, but sickness leave was shorter in the intervention group than in the control group. Hence, this study documents that investing in a treatment programme pays off for the company in terms of increased return rates of sick patients.

Two other recent studies among dentists (Te Brake, Gorter, Hoogstraten \& Eijkman, 2001) and among a heterogeneous group of employees (Leffers, Vergunst, Kleber, Stroebe \& Hak, 2000) showed highly similar results. In both cases, compared to the control group, the group that participated in the burnout workshop showed a significant decrease in exhaustion, whereas no significant difference was observed for professional efficacy. In the heterogeneous group a small reduction was found in employee cynicism as well. In the dentist's study, in addition to the control group that did not participate, another group of dentists who took action on their own initiative was distinguished. Interestingly, the latter group showed similar beneficial effects as the group who participated in the workshop. Moreover, long-term beneficial effects at the one-year follow-up were exclusively found in the group who took action on their own and not in the group that participated in the workshop.

Finally, De Geus, Van Son, Le Blanc and Schaufeli (2000) carried out a burnout prevention training in nine functional teams of oncology care providers, using a participatory action research approach that focused on improving the work situation rather than on changing the individual (see also, Le Blanc \& Schaufeli, 2003). Twenty teams served as controls and measures were taken before the training programme, that consisted of six monthly half-day sessions, immediately after the programme finished, and at follow-up six months later. Immediately after the training, compared to the control teams members of the experimental teams showed significant lower levels of exhaustion. Unfortunately, this beneficial effect had disappeared at the six months follow-up. Obviously, the decrease in exhaustion levels was short-lived.

In sum: compared to the booming business of combating burnout and compared to the importance of demonstrating effectiveness, the number of well-designed evaluation studies is rather small. Overall, the most recent studies confirm the earlier conclusions concerning the effectiveness of interventions. These studies were chosen in such a way as to reflect typical findings at the various levels of intervention: (1) individual, cognitivebehaviourally based interventions are successful in reducing burnout and they also seem to increase return rates to work; (2) burnout workshops for specific groups, like dentists or for heterogeneous groups of employees, are particularly successful in reducing levels of exhaustion; however it seems that employees relapse unless they are motivated to continue on their own initiative; (3) interventions that aim at improving the work situation seem to be likewise effective in reducing exhaustion levels, but again this positive result is rather short-term.

The future of burnout research

It is a truism that science progresses slowly, and burnout research is not an exception to this rule. As we have seen in the previous section, in the past ten years some progress has been made but there is still a lot of work to be done. In this concluding section I will draw up a research agenda that may guide our future efforts.

\section{Measurement and conceptualisation}

From a technical, psychometric point of view the MBI is a good instrument. Yet, some questions may be raised about its validity that need to be addressed in the near future. From a clinical psychological perspective the MBI does not cover the whole range of symptoms that are observed among employees with severe burnout. Most notably cognitive impairment and (neurasthenic) distress symptoms are lacking, whereas reduced professional efficacy does not seem to play such an important role. This calls for a new burnout instrument - perhaps partly based on the MBI - that can be used for individual assessment in clinical practice. Of course, this includes the establishment of appropriate cut-off points that allow to discriminate between various levels of burnout (see below).

From a theoretical point of view, it appears that exhaustion and cynicism are the core symptoms of burnout, that represent the energetic or arousal component and the identification or attitudinal component, respectively. In fact, burnout represents the negative pole of both dimensions: exhaustion signifies low energy whereas cynicism signifies low identification with one's job. Precisely these two core dimensions are assessed by a recently developed burnout measure, the OLBI (Demerouti et al., 2002), which can be used as an alternative for the MBI. 
Recently, is has been proposed to study the 'opposite' of burnout in order to cover the entire continuum of work-related experiences, ranging form negative (burnout) to positive (job engagement) (see Maslach, Schaufeli \& Leiter, 2001). The positive antipode of burnout is characterised by vigour (high energy) and dedication (strong identification). In addition, a third element is distinguished - absorption - which most likely plays a less central role in the engagement concept. The first psychometric results with a measure that assesses these three characteristics of engagement - the Utrecht Work Engagement Scale - are encouraging (Schaufeli, Salanova, González-Romá \& Bakker, 2002; Schaufeli, Martínez, Marques-Pinto, Salanova \& Bakker, 2002). Hence, instead of exclusively focusing on negative work related experiences, future research should also include positive work experiences in order to arrive at a more balanced picture of employee (un)well-being.

It has become increasingly clear that burnout is not a helpersyndrome that exclusively occurs in the human services. Therefore, burnout should in future also be studied outside the human services in order to verify if similar results are obtained as in the numerous studies that were carried out among employees who do people work. In order to make possible a direct comparison between human services and non-human services, the MBI-GS can be used in both contexts. Of course, when the MBI-GS is used among helpers, the specific interpersonal quality of burnout (depersonalisation) is lost. So when one is interested in both, comparing burnout across different professions, as well as assessing the employee's attitude towards recipients, the depersonalisation scale of the MBIHSS/ES should be included in addition to the MBI-GS.

\section{Mild and severe burnout}

Many professionals are confronted with cases of severe or clinical burnout, yet this group is seriously under-researched. Consequently, the crucial question whether or not fundamental differences exist between mild and severe burnout remains unanswered. Also, it is not clear yet as to what extent, and under what conditions mild burnout might develop into serious burnout. These questions ask for collaboration with occupational physicians, psychiatrists and clinical psychologists. In order to study severe burnout, not only psychometric work has to be done on the MBI or other self-report inventories to develop clinically validated cut-offs, but other types of assessment tools should be developed and researched as well, such as diagnostic guidelines as issues by the Royal Dutch Medical Association. Finally, in studying severe burnout patients psychophysiological parameters should not be overlooked, since theorising and preliminary empirical results suggest that burnout might be related to a disregulation of the so-called hypothalamic-pituitary-adrenal axis (Van Doornen, 2001). Indeed, Melamed et al. (1999) found a relationship between burnout and salivary cortisol levels. Hence, research on, for instance, the role of stress hormone cortisol might prove to be an interesting avenue that may uncover psychophysiological differences between burnout and depression.

\section{Epidemiology}

Although epidemiological studies are quite straightforward from a methodological point of view, they are practically speaking very laborious since such studies require large and representative samples. In principle epidemiological studies estimate the incidence and prevalence of burnout cases. However, in order to do this one needs a 'case-finding' instrument. Basically, the MBI can play this role, provided that clinically validated cut-offs exist that allow discrimination between burnout and non-burnout cases. So far, this only seems to be the case in The Netherlands.

As soon as such cut-offs are available for other countries as well, international comparisons on the incidence and prevalence of burnout (across occupations) can be made. The next best option is to draw similar representative samples from different countries or occupations and to compare their mean scores on the various burnout dimensions, thereby controlling for relevant confounders (e.g. Van Horn, Schaufeli, Greenglass \& Burke, 1997).

\section{Cross-cultural perspective}

A true cross-cultural perspective on burnout is still lacking, although various cross-national studies have been carried out (for an overview see: Golembiewski, Scherb \& Boudreau, 1993 and Savicki, 2003). Instead of post-hoc explanations of differences in burnout across nations, we need the testing of a priori formulated cross-cultural hypothesis. For instance, it could be reasoned that lack of reciprocity plays a different role in the development of burnout in individualistic cultures as opposed to collectivistic cultures. Perhaps in individualistic cultures, social exchange relationships between individuals (inter-personal reciprocity) might play a crucial role in causing burnout, whereas in collectivistic cultures social exchange relationships with the group (individual-group reciprocity) might be pivotal. On a more basic level, it remains to be seen whether or not, such social psychological explanations are valid at all in cultural contexts that differ considerably from North America or Western Europe.

\section{Organisational relevance}

The traditional focus of burnout research on self-reports and experienced work characteristics has to be supplemented by a focus on those objective aspects of the work situation that can be influenced by management (e.g. caseload, performance feedback, job control) and on outcomes that have direct or indirect economical impact (e.g. sick leave, efficiency, performance, customer satisfaction). This calls for collaboration with economists and business administration researchers. Burnout as a psychological phenomenon will be taken seriously by the management of organisations only to the extent to which it demonstrably contributes to poor business performance. Following this line of reasoning, organisations will be inclined to invest in preventive, organisational based anti-burnout programmes when they believe positive results can be obtained in terms of lower sickness and turnover rates and better performance. The burden of proof rests on the shoulders of applied researchers.

\section{Longitudinal designs: causes and consequences}

Our knowledge on the causes and consequences of burnout is still rather limited, at least when we draw upon the most sophisticated longitudinal studies. In a way, burnout research finds itself in a paradox: when sophisticated designs are used that seek to explain changes in burnout levels, a methodological artifact is introduced that is caused by the high stability of burnout across time, so that null results are usually obtained; when, in contrast, less sophisticated designs are used that do not control for prior burnout levels one cannot be sure whether the obtained results justify causal interpretation. A possible way out of this dilemma is to monitor a group of employees during a period of change, such as the transition from school to employment, or during organisational restructuring. This makes it more likely that changes in burnout occur across time. Unfortunately, Burisch (2002), who followed beginning nurses during the first three years of their career, was not very successful in disentangling cause and effect. Nevertheless, this avenue of longitudinal research needs to be further explored. In addition, new ways of analysing longitudinal data that emphasise individual patterns of change rather than group patterns (e.g. latent growth curve modeling) might also contribute to solving the dilemma outlined above. Finally, alternative research methods such as experienced sampling might be used to study patterns of change within persons during relative brief periods of time. In experiences sampling, subjects have to respond several times a day at random moments to a beep of a hand-held computer by answering several questions on their current experiences that 
appear on the display. These responses can be linked to psychophysiological markers that may be recorded simultaneously by using an ambulatory device. This allows, for instance, to study the covariance of subjective experiences and psychophysiological parameters of burnout patients and controls across the day.

\section{Theoretical explanations}

A grand unifying theory of burnout will always remain a dream, simply because the phenomenon is too complex and multi-faceted. Indeed, various theoretical perspectives on burnout exist at various levels of aggregation. There is no a priori reason why theories at one particular level of aggregation are superior to theories at another level. What counts, however, is that theoretical approaches are convincingly supported by empirical results; the proof of the pudding is in the eating. So far, particularly social psychological explanations of burnout have received considerable empirical supported. From a social psychological point of view burnout is understood as a phenomenon that develops primarily in a social context, and in order to understand its development and persistence attention has to be paid to the way individuals perceive, interpret and construct the behaviours of others at work. As yet, theoretical explanations at the individual and at the organisational level that can draw upon systematic empirical evidence are almost absent. So, there is quite some work to do in these two areas. Basically, either existing psychological theories can be applied to burnout, or specific 'local' theories on burnout may be developed. As far as individual approaches are concerned, research collaboration with psychiatrists and clinical psychologists seems to be necessary. Explanations of burnout at the societal and cultural level - the highest level of aggregation - are beyond the scope of psychology and should be investigated by historians, anthropologists and sociologists.

\section{Interventions}

Research on the effectiveness of interventions is quite straightforward. Like epidemiological research, this type of investigation it is not very complicated from a methodologically point of view, but it is likewise difficult to carry out in practice. The latter applies particularly to organisation-based interventions for which it is often impossible to employ a neat (quasi-) experimental pre-test, post-test control-group design, as is recommended in the textbooks on evaluation research. Instead, alternative methodologies such as organisational case studies could be used (see Kompier \& Cooper, 1999). To date, this has hardly been done for burnout interventions. In addition to outcome effectiveness and the evaluation of the intervention process itself, attention should also be paid to the cost-effectiveness of intervention programmes. A cost-effective intervention might convince management to adopt that particular strategy. This calls for research collaboration with economists, as recently advocated by DeRango and Franzini (2003).

As a final note on the future research agenda of burnout I would like to emphasise the importance of collaboration with practitioners like occupational physicians, psychiatrists, and clinical psychologists, as well as with fellow scholars especially from such fields as epidemiology, physiology, economics and business administration. Burnout is too important to leave it exclusively to (industrial) psychologists.

\section{REFERENCES}

Aiken, L.H., Clarke, S.P., Sloane, D.M., Sochalski, J. \& Silber, J.H. (2002). Hospital nurse staffing and patient mortality, nurse burnout and job dissatisfaction. Journal of the American Medical Association, 288, 1987-1993.
Bakker, A., Demerouti, E. \& Schaufeli, W.B (2002). Validation of the Maslach Burnout Inventory - General Survey: An internet study. Anxiety, Stress and Coping, 15, 245-260.

Bakker, A.B. \& Schaufeli, W.B. (2000). Burnout contagion processes among teachers. Journal of Applied Social Psychology, 30, 2289-2308.

Bakker, A.B., Schaufeli, W.B., Demerouti, E., Janssen, P.M.P., Van der Hulst, R. \& Brouwer, J. (2000a). Using equity theory to examine the difference between burnout and depression. Anxiety, Stress and Coping, 13, 247-268.

Bakker, A., Schaufeli, W.B. \& Van Dierendonck, D. (2000b) Burnout: Prevalentie, risicogroepen en risicofactoren [Burnout: prevalence, risk groups and risk factors]. In: I.L.D.Houtman, W.B. Schaufeli \& T. Taris, (Eds.). Psychische vermoeidheid en werk: Cijfers, trends en analyses (pp. 65-82). Alphen a/d Rijn: Samsom.

Bakker, A., Schaufeli, W.B., Sixma, H.J., Bosveld, W. \& Van Dierendonck, D. (2000c). Patient demands, lack of reciprocity and burnout: A five-year longitudinal study among general practitioners. Journal of Organizational Behavior, 21, 425-441.

Boles, J.S., Dean, D.H., Ricks, J.M., Short, J.C. \& Wang, G. (2000). The dimensionality of the Maslach Burnout Inventory across small business owners and educators. Journal of Vocational Behavior, 56, 12-34.

Bouman, A.H., te Brake, H. \& Hoogstraten, J. (2002). Significant effects due to rephrasing the Maslach Burnout Inventory's personal accomplishment items. Psychological Reports, 91, 825-826.

Brenninkmeier, V. \& Van Yperen, N.W. (1999). Diagnostiek van burnout door middel van de Utrechtse Burnout Schaal [Diagnosing burnout by means of the Utrecht Burnout Scale]. Nederlands Tijdschrift voor de Pychologie, 54, 105-108.

Brenninkmeier, V. \& Van Yperen, N.W. (2003). How to conduct research on burnout: advantages and disadvantages of a unidimensional approach in burnout research. Occupational and Environmental Medicine, 60, Supplement 1, 16-20.

Burisch, M. (2002). A longitudinal study of burnout: The relative importance of dispositions and experiences. Work and Stress, $16,1-17$

Burke, R.J., Greenglass, E. \& Schwarzer, R. (1996). Predicting teacher burnout over time: effects of work stress, social support, and self doubts on burnout and its consequences. Anxiety, Stress and Coping, 9, 261-275.

Buunk, B.P. \& Schaufeli, W.B. (1999). Reciprocity in interpersonal relationships: PRIVATE An evolutionary perspective on its importance for health and well-being. In W. Stroebe \& M. Hewstone (Eds.), European Review of Social Psychology, 10, 260-291.

Buunk, B.P., Ybema, J.F., Van der. Zee, K., Schaufeli, W.B. \& Gibbons, F.X. (2001). Affect generated by social comparisons among nurses high and low burnout. Journal of Applied Social Psychology, 31, 1500-1520.

Byrne, B. (1991). The Maslach Burnout Inventory: Validating factorial structure and invariance across intermediate, secondary and university educators. Multivariate Behavioral Research, 26, 583-605.

Cordes, C. L. \& Dougherty, T. W. (1993). A review and an integration of research on job burnout. Academy of Management Review, 18, 621-656.

Cordes, C.L., Dougerthy, T.W. \& Blum, M. (1997). Patterns of burnout among managers and professionals : a comparison of models. Journal of Organizational Behavior, 18, 685-701.

De Geus, A.C., Van Son, A.M., LeBlanc, P.M. \& Schaufeli, W.B. (2000). 'Take Care!' Een teamgerichte interventie ter bevordering van welzijn op het werk [Take Care! A team-based intervention to improve well-being at work] Houten: Bohn Stafleu Van Loghum.

DeRango, K. \& Franzini, L. (2003). Economic evaluations of workplace health interventions: Theory and literature review. In J.C. Quick \& L.E. Tetrick, Handbook of Occupational Health Psychology (pp. 417-430). Washington, DC: American Psychological Association. 
Densten, I.L. (2001). Re-thinking burnout. Journal of Organizational Behavior, 22, 833-847.

Demerouti, E., Bakker, A.B., Vardakou, I. \& Kantas, A. (2002). The convergent validity of two burnout instruments: A multitrait-multimethod analysis. European Journal of Personality Assessment, 18, 296-307.

Demerouti, E., Bakker, A.B., Nachreiner, F. \& Schaufeli, W.B. (2000). A model of burnout and life satisfaction among nurses. Journal of Advanced Nursing, 32, 454-464.

Demerouti E., Bakker, A.B., Nachreiner, F. \& Schaufeli, W.B. (2001). The Job Demands-Resources model of burnout. Journal of Applied Psychology, 86, 499-512.

Enzmann, D., Schaufeli, W.B. \& Girault, N. (1995). The validity of the Maslach Bunrout Inventory in three national samples. In: L. Bennett, D. Miller \& M. Ross (Eds.), Health workers and AIDS: Research, interventions and current issues (pp. 131-150). Chur: Harwood.

Enzmann, D., Schaufeli, W.B., Janssen, P. \& Rozeman, A. (1998). Dimensionality and validity of the Burnout Measure. Journal of Occupational and Organisational Psychology, 71, 331-351.

Etzion, D. (2003). Annual vacation: Duration of relief from job stressors and burnout. Anxiety, Stress and Coping, 16, 1-14.

Evans, B.K. \& Fischer, D.G. (1993). The nature of burnout: A study of the three-factor model of burnout in human services and non-human services samples. Journal of Occupational and Organizational Psychology, 66, 29-38.

Garden, A. M. (1987). Depersonalization: A valid dimension of burnout. Human Relations, 40, 545-560.

Garman, A.N., Corrigan, P.W. \& Morris, S. (2002). Staff burnout and patient satisfaction: Evidence of relationships at the care unit level. Journal of Occupational Health Psychology, 7, 235-241.

Glass, D.C. \& McKnight, J.D. (1996). Perceived control, depressive symptomatology, and professional burnout: A review of the evidence. Psychology and Health, 11, 23-48.

Gorter, R.C., Albrecht, G., Hoogstraten, J. \& Eijkman, A.J. (1999). Factorial validity of the Maslach Burnout Inventory - Dutch version (MBI-NL) among dentists. Journal of Organizational Behavior, 20, 209-217.

Golembiewski, R.T., Munzenrider, R.F. \& Stevenson, J.G. (1986). Stress in organizations: Toward a phase model of burnout. New York: Praeger.

Golembiewski, G.T., Boudreau, R.A., Munzenrider, R.F. \& Luo, H. (1996). Global burnout: A worldwide pandemic explored by the phase model. Greenwich, CT: JAI Press.

Golembiewski, R.T, Scherb, K. \& Boudreau, R.A. (1993). Burnout in cross-national settings: Generic and model-specific perspectives. In W. B. Schaufeli, C. Maslach \& T. Marek (Eds.), Professional burnout: Recent developments in theory and research. Series in applied psychology: Social issues and questions (pp. 217-236). Washington, D.C.: Taylor \& Francis.

Green, D.E., Walkey, F.H. \& Taylor, A.J.W. (1991), The threefactor structure of the Maslach Burnout Inventory. Journal of Social Behavior and Personality, 6, 453472.

Harrington, D., Bean, N., Pintello, D. \& Mathews, D. (2001). Job satisfaction and burnout: Predictors to leave a job in a military setting. Administration in Social Work, 25, 1-16.

Hillhouse, J.J., Adler, C.M. \& Walters, D.N. (2000). A simple model of stress, burnout and symptomatology in medical residents: A longitudinal study. Psychology, Health and Medicine, 5, 63-73.

Holland, P.J., Michael, W.B. \& Kim, S. (1994). Construct validity of the educators survey for a sample of middle school teachers. Educational and Psychological Measurement, 54, 822-829.

Hoogduin, C., Schaap, C. Methorst, G. Peters van Neyenhof, C. \& Van de Griendt, J. (2001). Burnout: Klinsich beeld en diagnostiek [Burnout: Clinical description and diagnosis]. In C.A.L. Hoogdduin, W.B. Schaufeli, C.P.D.R. Schaap \& A.B. Bakker (Eds.). Behandelingsstrategieën bij burnout (pp. 1320). Houten: Bohn Stafleu VanLoghum.

Hoogduin, C. (2001). Richtlijnen en behandelingsstrategieën [Guidelines and strategies for treatment]. In C.A.L.
Hoogdduin, W.B. Schaufeli, C.P.D.R. Schaap \& A.B. Bakker (Eds.). Behandelingsstrategieen bij burnout (pp. 96-101). Houten: Bohn Stafleu VanLoghum.

Houtman, I.L.D., Smulders, P.G.W. \& Klein Hesselink, D.J. (2002). Trends in arbeid 2002 [Trends in work]. Alphen a/d Rijn: TNO Arbeid/Kluwer.

Iverson, R.D., Olekans, M. \& Erwin, P. (1998). Affectivity, organizational stressors, and absenteeism: A causal model of burnout and its consequences. Journal of Vocational Behavior, 52, 1-23.

Kompier, M. \& Cooper, C. (Eds.) (1999). Prevention stress, improving productivity: European case studies in the workplace. London: Routledge.

Landsbergis, P. (2003). The changing organization of work and the safety and health of working people: A commentary. Journal of Occupational and Environmental Medicine, 45, 6172 .

Laitinen-Krispijn, S. \& Bijl, R. (2000). Mental disorders and employee sickness absence: The NEMESIS study. Social Psychiatry and Epidemiology, 35, 71-77.

Le Blanc, P.\& Schaufeli, W.B. (2003). Burnout among oncology care providers: Radiation assistants, physicians and nurses. In M.F. Dollard, A.H. Winefield \& H.R. Winefield (Eds.). Occupational stress in the service professions (pp. 143-167). London: Taylor \& Francis.

Lee, R.T. \& Ashforth, B.E. (1993). A longitudinal study of burnout among supervisors and managers: Comparison between the Leiter and Maslach (1988) and Golembiewski et al. (1986) models. Organizational Behavior and Human Decision Processes, 54, 369-398.

Lee, R.T. \& Ashforth, B.E. (1996). A meta-analytic examination of the correlates of the three dimensions of job burnout. Journal of Applied Psychology, 81, 123-133.

Leffers, F., Vergunst, A., Kleber, R., Stroebe, M. \& Hak, E. (2000). Stress op het werk de baas: Resultaten van een stresshanteringstraining [Stress in the task of the supervisor: Results of a stress management training.] Gedrag \& Gezondheid, 28, 12-22.

Leiter, M. P. (1993). Burnout as a developmental process: Consideration of models. In W. B. Schaufeli, C. Maslach \& T. Marek (Eds.), Professional burnout: Recent developments in theory and research. Series in applied psychology: Social issues and questions (pp. 237-250). Washington, D.C.: Taylor \& Francis.

Leiter, M.P. \& Maslach, C. (1988). The impact of interpersonal environment on burnout and organizational commitment. Journal of Organizational Behavior, 9, 297308.

Leiter, M.P. \& Schaufeli, W.B. (1996). Consistency of the burnout construct across occupations. Anxiety, Stress and Coping, 9 , 229-243.

Leiter, M.P., Harvie, P. \& Frizzell, C. (1998). The correspondence of patient satisfaction and nurse burnout. Social Science and Medicine, 10, 1611-1617.

Low, G.S., Cravens, D.W., Grant, K. \& Moncrief, W.C. (2001). Antecedents and consequences of salesperson burnout. European Journal of Marketing, 35, 587-611.

Maslach, C. (1982). Burnout: A social psychological analysis. In J. W. Jones (Ed.), The burnout syndrome (pp. 30-53). Park Ridge, IL: London House.

Maslach, C. \& Jackson, S. E. (1984). Burnout in organizational settings. In S. Oskamp (Ed.), Applied Social Psychology Annual 5 (pp. 133154). Beverly Hills, CA: Sage.

Maslach, C. \& Jackson, S. E. (1986). Maslach Burnout Inventory. Manual ( $2^{\text {nd }}$ ed.). Palo Alto, CA: Consulting Psychologists Press.

Maslach, C., Jackson, S.E. \& Leiter, M. (1996). Maslach Burnout Inventory. Manual (3rd ed.). Palo Alto, CA: Consulting Psychologists Press.

Maslach, C., Schaufeli, W.B. \& Leiter, M.P. (2001). Job burnout. Annual Review of Psychology, 52, 397-422.

McKnight, J.D. \& Glass, D.C. (1995). Perceptions of control, burnout, and depressive symptomatology: A replication and extension. Journal of Consulting and Clinical Psychology, 63, 490-494. 
McManus, I.C., Winder, B.C. \& Gordon, D. (2002). The causal links between stress and burout in a longitudinal study of UK doctors. The Lancet, 359, 2089-2090.

Meijman, T.F. \& Schaufeli, W.B. (1996). Psychische vermoeidheid en arbeid [Mental fatigue and work]. De Psycholoog, 31, 236-243.

Melamed, S., Ugarten, U., Shirom, A., Kahana, L., Lerman, Y., \& Froom, P. (1999). Chronic burnout, somatic arousal and elevated cortisol levels. Journal of Psychosomatic Research, 46, 591-598.

Mohren, D., Swaen, G., Kant, I.J., Van Amelsvoort, L., Born, P. \& Galama, J. (in press). Common infections and the role of burnout in a Dutch working population. Journal of Psychosomatic Research.

Paine, W.S. (1982). The burnout syndrome in context. In J. W. Jones (Ed.), The burnout syndrome (pp. 1-29). Park Ridge, IL: London House.

Paoli, P. (2001). Third survey on the work environment 2000. European Foundation for the Improvement of Living and Working Conditions, Dublin: Loughlingstown House.

Pines, A.M., Aronson, E. \& Kafry, D. (1981). Burnout: From tedium to personal growth. New York: Free Press.

Prosser, D., Johnson, S., Kuipers, E., Dunn, G., Szmukler, G., Reid, Y., Bebbington P., \& Thornicroft, G. (1999). Mental health, "burnout" and job satisfaction in a longitudinal study of mental health staff. Social Psychiatry and Psychiatrical Epidemiology, 34, 295-300.

Rösing, I. (2003). Die ausgebrannte Burnoutforschung: Eine wissenschaftssoziologische und kulturanthropologische Kritik der internationalen Burnoutforschung [The burned out burnout research: A sociology of science and cultural anthropological criticism of international burnout research]. Heidelberg: Asanger.

Ross, M.W., Greenfield, A.A. \& Bennett, L. (2000). Predictors of dropout and burnout in AIDS volunteers: A longitudinal study. AIDS Care, 11, 723-731.

Salanova, M. \& Schaufeli, W.B. (2000). Exposure to technology and its relationship to burnout. Behavior and Information Technology, 19, 385-392.

Savicki, V. (2002). Burnout across thirteen cultures: Stress and coping in child and youth care workers. Westport, CT: Preager.

Schaufeli, W. (2003). The balance of give and take: Toward a social exchange model of burnout. Manuscript submitted for publication.

Schaufeli, W.B. \& Buunk, B.P. (2002) Burnout: An overview of 25 years of research and theorizing. M.J. Schabracq, J.A.M. Winnubst, C.L. Cooper (Eds.), Handbook of work and health psychology (pp. 383-425). Chichester: Wiley.

Schaufeli, W.B. \& Janczur, B. (1994). Burnout among nurses: A Polish-Dutch comparison. Journal of Cross-Cultural Psychology, 25, 95-113.

Schaufeli, W.B., G.J. Keijsers, D. Reis-Miranda (1995). Burnout, technology use, and ICU-performance. In: S.L. Sauter \& L.R. Murphy (Eds.), Organizational risk factors for job stress (pp. 259-272). Washington, D.C.: American Psychological Association.

Schaufeli, W.B., Maslach, C. \& Marek, T. (1993). The future of burnout. In W. B. Schaufeli, C. Maslach \& T. Marek (Eds.), Professional burnout: Recent developments in theory and research (pp. 253-261). Washington, D.C.: Taylor \& Francis.

Schaufeli, W.B., Salanova, M., Gonzalez-Roma. V. \& Bakker, A.B. (2002) The measurement of engagement and burnout: A confirmative analytic approach. Journal of Happiness Studies, 3, 71-92.

Schaufeli, W.B., Martinez, I., Marques-Pinto, A. Salanova, M. \& Bakker, A.B. (2002). Burnout and engagement in university students: A cross national study. Journal of Cross-Cultural Psychology, 33, 464-481.

Schaufeli, W.B., Leiter, M.P., Maslach, C. \& Jackson, S.E. (1996). Maslach Burnout Inventory - General Survey. In C. Maslach, S.E. Jackson \& M.P. Leiter, The Maslach Burnout Inventory (3rd ed.) - Test Manual. Palo Alto: Consulting Psychologists Press.
Schaufeli, W.B. Bakker, A., Schaap, C. Kladler, A. \& Hoogduin, C.A.L. (2001) On the clinical validity of the Maslach Burnout Inventory and the Burnout Measure. Psychology and Health, $16,565-582$

Schaufeli, W.B. \& Van Dierendonck, D. (1995). A cautionary note about the cross-national and clinical validity of cut-off points for the Maslach Burnout Inventory. Psychological Reports, 76, 1083-1090.

Schaufeli, W.B. \& Van Dierendonck, D. (2000) Handleiding van de Utrechtse Burnout Schaal (UBOS) [Test manual of the Utrecht Burnout Scale]. Lisse: Swets \& Zeitlinger.

Schaufeli, W.B. \& Enzmann, D. (1998). The burnout companion to study and research: A critical analysis. London: Taylor \& Francis.

Schaufeli, W.B., Enzmann, D. \& Girault, N. (1993). The measurement of burnout: A review. In W.B. Schaufeli, C. Maslach \& T. Marek (Eds). Professional burnout: Recent developments in theory and research (pp. 199-215). Washington: Taylor \& Francis.

Schmidt, A.J.M. (2000). De psychologie van overspanning: Theorie en praktijk [The psychology of overstrain: Theory and practice]. Boom: Meppel.

Schutte, N., Toppinnen, S., Kalimo, R. \& Schaufeli, W.B (2000). The factorial validity of the Maslach Burnout Inventory General Survey (MBI-GS) across nations and occupations. Journal of Occupational and Organizational Psychology, 73 53-66.

Shirom, A. (1989). Burnout in work organizations. In C. L. Cooper \& I. T. Robertson (Eds.), International Review of Industrial and Organizational Psychology 1989 (pp. 25-48). Chichester: Wiley.

Shirom, A. (2003). Job-related burnout: A review. . In J.C. Quick \& L.E. Tetrick, Handbook of Occupational Health Psychology (pp. 245-264). Washington, DC: American Psychological Association.

Sing, J. (2000). Performance productivity and quality of frontline employees in service organizations. Journal of Marketing, 64, 15-34.

Taris, T.W., Peeters, M.C.W., Le Blanc, P,M., Schreurs, P.J.G. \& Schaufeli, W.B. (2001) From inequity to burnout: The role of job stress. Journal of Occupational Health Psychology, 6, 303-323.

Taris, T.W., Schreurs, P.J. \& Schaufeli, W.B. (1999). Construct validity of the Maslach Burnout Inventory - General Survey: A two-sample examination of its factor structure and correlates. Work and Stress, 13, 223-237.

Taris, T., Schaufeli, W.B., Schreurs, P. \& Caljé, D. (2000). Opgebrand in het onderwijs: Stress, psychische vermoeidheid en ziekteverzuim onder leraren [Burnout in education: Stress, mental fatigue, and absenteeism among teachers In: I.L.D. Houtman, W.B. Schaufeli \& T. Taris, (Eds.). Psychische vermoeidheid en werk: Cijfers, trends en analyses (pp. 97-106) Alphen a/d Rijn: Samsom.

Taris, T., Stoffelsen, J. Bakker, A., Schaufeli, W. \& Van Dierendonck, D. (2002). Verschillen in bunroutrisico tussen functies en individuen: Wat is de rol van regelmogelijkheden? [Differences in burnout risks between jobs and individuals: what is the role of autonomy?] Gedrag \& Gezondheid, 30, 17-29.

Taris, T., Le Blanc, P., Schaufeli, W. \& Schreurs, P. (2003). The quest for cuasal telationships among the subsclaes of the Masalch Burnout Inventory: Firtile or futile. Manuscript submitted for publication.

The Lancet. (1994). Burnished or burnt out: The delights and dangers of working in health (editorial). The Lancet, 344 (8937), 1583-1584.

Te Brake, J., Gorter, R., Hoogstraten, J. \& Eijkman, M. (2001). Burnout intervention among Dutch dentists: long term effects. European Journal of Oral Science, 109, 380-387.

Toppinen-Tanner, S., Kalimo, R. \& Mutanen, P. (2002). The process of burnout in white-collar and blue collar jobs: Eight year prospective study of exhaustion. Journal of Organizational Behavior, 23, 555-570. 
Van der Klink, J., Blonk, R., Schene, A. \& van Dijk, F. (2001). The benefits of interventions for work-related stress. American Journal of Public Health, 91, 270-276.

Van der Klink, J., Blonk, R., Schene, A. \& van Dijk, F. (in press). Reducing long-term sickness absence by an activating intervention in adjustment disorders: A cluster randomized controlled design. Journal of Occupational and Environmental Medicine.

Van Dierendonck, D. \& Mevissen, N. (2002). Aggressive behavior of passengers, conflict management behavior and burnout among trolley car drivers. International Journal of Stress Management, 9, 345-357.

Van Dierendonck, D., Schaufeli, W.B. \& Buunk, B.P. (2001). Towards a process model of burnmout: Results from a secondary analysis. European Journal of Work and Organizational Psychology, 10, 41-52.

Van Doornen, L. (2001). Psychofysiologie van burnout [Psychofysiology of burnout]. In C.A.L. Hoogdduin, W.B. Schaufeli, C.P.D.R. Schaap \& A.B. Bakker (Eds.).
Behandelingsstrategiën bij burnout (pp. 40-50). Houten: Bohn Stafleu VanLoghum.

Van Horn, J.E., Schaufeli, W.B., Greenglass, E.R. \& Burke, R.J. (1997). A Canadian-Dutch comparison of teachers' burnout. Psychological Reports, 81, 371-382.

Van Horn, J.E., Taris, T.W., Schaufeli, W.B. \& Schreurs, P.J.G. (in press). A multi-dimensional approach to measuring teacher well-being. Journal of Occupational and Organisational Psychology.

Wolpin, J., Burke, R.J. \& Greenglass, E. R. (1991). Is job satisfaction an antecedent or a consequence of psychological burnout? Human Relations, 44, 193-209.

Zijlstra, F. \& De Vries, Y. (2001). Burnout en de bijdrage van socio-biografische en werkgebonden variabelen [Burnout and the contribution of socio-demographic and work related variables] In: I.L.D.Houtman, W.B. Schaufeli \& T. Taris, (red.). Psychische vermoeidheid en werk: Cijfers, trends en analyses (pp. 83-106). Alphen a/d Rijn: Samsom. 